\title{
Redes neurais artificiais e modelos alométricos aplicados para estimativa de volume e altura em Eucalyptus urophylla S. T. Blake
}

\author{
Fabrício Assis Leal ${ }^{1}$ Glória da Silva Almeida Leal ${ }^{2 *}$ Thaís Costa da Silva®²
}

${ }^{1}$ Universidade de Brasília, Campus Universitário Darcy Ribeiro - Asa Norte, CEP: 70910-900, Brasília, DF, Brasil

${ }^{2}$ Universidade Federal do Acre, Rodovia BR 364, Km 04 - Distrito Industrial, CEP: 69920-900 78060-900, , Rio Branco - AC, Brasil

\section{Original Article \\ *Corresponding author: gloriaalmeidaleal@gmail.co $\mathrm{m}$}

\section{Keywords:}

Eucalipto

Modelos hipsométricos e volumétricos

RNA

Palavras-chave:

Eucalyptus

Hypsometric and volumetric models

ANN

Received in

Accepted on

Published in

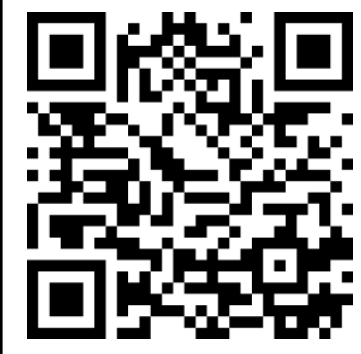

DOI: http://dx.doi.org/ 10.34062/afs.v7i3.10720

\section{(cc) BY}

RESUMO: Redes neurais artificiais (RNA) destacam-se como ferramentas alternativas na modelagem florestal, com resultados muitas vezes superiores em relação aos métodos tradicionais de regressão. Este estudo objetivou avaliar se as estimativas de volume e altura, obtidas por redes neurais artificiais e modelos alométricos, são compatíveis ao método tradicional de cubagem rigorosa. Para obtenção dos dados foram cubadas, pelo método de Hohenadl, 394 árvores de Eucalyptus urophylla. Destas árvores, $70 \%$ foram utilizadas nos ajustes dos modelos hipsométricos, volumétricos e para treinamento da RNA e $30 \%$ fizeram parte da validação. Para selecionar as melhores equações e RNA observou-se as melhores estatísticas de ajuste e precisão. Estatisticamente, não houve diferença entre os dados da cubagem em campo e as estimativas, ao nível de $5 \%$ de significância. Tanto os modelos de regressão quanto as RNA apresentaram bons ajustes, no entanto, as RNA foram superiores em desempenho, pois apresentaram Syx de a $2 \%$ no treinamento e $2,5 \%$ na validação, para variável altura, e Syx de $6,5 \%$ no treinamento e $5,1 \%$ na validação, para o volume.

\section{Artificial neural networks and allometric models for estimating the volume and height of Eucalyptus urophylla S. T. Blake}

\begin{abstract}
Artificial neural networks (ANN) stand out as alternative tools in forest modeling, with results often superior to traditional regression methods. This study aimed to evaluate whether the estimates of volume and height, obtained by artificial neural networks and allometric models, are compatible with the traditional method of rigorous cubing. To obtain the data, 394 Eucalyptus urophylla trees were cubed, using the Hohenadl method. Of these trees, $70 \%$ were used to adjust the hypsometric, volumetric and ANN training models and 30\% were part of the validation. To select the best equations and ANN, the best fit and precision statistics were observed. Statistically, there was no difference between the field cubing data and the estimates, at the 5\% level of significance. Both the regression models and the ANNs showed good adjustments, however, the ANNs were superior in performance, as they presented Syx of $2 \%$ in training and $2.5 \%$ in validation, for height variable, and Syx of $6.5 \%$ in training and $5.1 \%$ in validation, for volume.
\end{abstract}


Introdução

No Brasil, 72,8\% das áreas de florestas plantadas são cultivadas com o eucalipto. A razão disso é devido o gênero Eucalyptus possuir uma das rotações e idade de corte mais curtas de árvores do mundo (IBÁ 2019), por consequência do seu rápido crescimento e do clima favorável (Gonçalves et al. 2017). Tudo isso é produto de avanços tecnológicos, que torna o Brasil referência mundial no setor de florestas plantadas de eucalipto, destacando-se com a maior produtividade de volume de madeira em $\mathrm{m}^{3} / \mathrm{ha}$ /ano do mundo (IBÁ 2019).

Ressalta-se que a rotação é uma das fases mais importantes para o planejamento do manejo florestal, no qual, seu principal objetivo é a maximização do lucro (Gonçalves et al. 2017). Entretanto, para definir a rotação é imprescindível conhecer o crescimento e a produção florestal. Assim, faz-se necessário o monitoramento, principalmente, dos incrementos das variáveis volume e altura do povoamento. Ademais, acompanhar o crescimento também é indispensável para o planejamento dos plantios florestais, sendo fundamental para quantificação dos mais variados produtos existentes no povoamento (Leite et al. 2011).

No entanto, como volume e altura são de difícil obtenção, utiliza-se equações alométricas para obter estimativas dessas variáveis em cada indivíduo da população (Miguel et al. 2014; David et al. 2016). Dessa forma, essas equações reduzem os custos do inventário florestal, com a otimização do tempo no levantamento dos dados (Binoti et al. 2013a; Mendonça et al. 2015), além de tornar o inventário menos laborioso.

Diversos estudos florestais apresentam alguns modelos e confirmam a eficácia dessas equações, dentre as pesquisas podemos citar os trabalhos realizados por Azevedo et al. (2011); Binoti et al. (2013b); Campos e Leite (2013); Leal, et al. (2015); Miguel et al. (2015); Santos, et al. (2015); Vibrans, et al. (2015); Mirzaei et al. (2016); Mugasha et al. (2016); Debastiani et al. (2019) dentre outros.

Mais recentemente, novas técnicas de predição que utilizam inteligência artificial, como redes neurais artificiais (RNA), também têm sido aplicadas nas mais diversas áreas, inclusive na florestal. Os mecanismos de funcionamento das redes são inspirados no funcionamento dos neurônios biológicos, onde cada neurônio constitui uma unidade de processamento simples, onde se opera uma equação matemática (função de ativação), em geral não linear, que processa a informação recebida e a transmite para outro neurônio (Braga et al. 2007). Em geral, uma rede neural é um sistema projetado para modelar da mesma forma que o cérebro realiza uma tarefa particular, onde é executada usando elementos eletrônicos ou é simulada por propagação em um computador digital (Haykin 2001).

Com potencial de uso no meio florestal (Almeida et al. 2014; Leal et al. 2015) a aplicação da inteligência artificial nessa área é recente, porém, tem sido frequente sua utilização para realizar estimativas de variáveis nas diversas linhas de pesquisas, apresentando resultados significativos e até melhores em relação aos modelos tradicionais de regressão. Além disso, diversos estudos confirmam a capacidade das RNA para estimar o volume, (Gorgens et al. 2009; Özçelik et al. 2010; Binoti et al. 2014), altura (Binoti et al. 2013a; Özçelik et al. 2013; Martins et al. 2016), afilamento (Leite et al. 2011; Nunes e Gõrgens 2016; Martins et al. 2017), crescimento (Castro et al. 2013; Lima et al. 2013; Binoti et al. 2015; Ashraf et al. 2015), estimativas de desmatamento (Leal et al. 2020), estimativas de variáveis biométricas (Fernandes et al. 2019).

Portanto, estudos sobre redes neurais artificiais são cada vez mais importantes no meio florestal, sendo que essas redes proporcionam ótimos resultados em diversas áreas (Vendruscolo et al. 2015). Dado o exposto, esta pesquisa teve por objetivo avaliar se as estimativas de volume $\left(\mathrm{m}^{3}\right)$ e altura (m) em Eucalyptus urophylla, obtidas por meio de redes neurais artificiais e por modelos alométricos, são compatíveis ao método tradicional de cubagem rigorosa.

\section{Material e Métodos}

Os dados utilizados para este estudo foram obtidos em Rio Verde/Goiás, em um plantio de Eucalyptus urophylla S. T. Blake, com 6,5 anos de idade, espaçamento de $3 \times 2 \mathrm{~m}$, pertencente à Cooperativa Agroindustrial dos Produtores Rurais do Sudoeste Goiano - COMIGO. O local onde foi realizado o trabalho compreende 116 hectares no total, dividido em sete talhões, entre os paralelos $18^{\circ}$ $00^{\prime} 45^{\prime \prime}$ e $18^{\circ} 01^{\prime} 45^{\prime}$ ' de latitude Sul, e entre os meridianos $50^{\circ} 52^{\prime} 45^{\prime \prime}$ e $50^{\circ} 53^{\prime} 15^{\prime}$ ' de longitude Oeste.

A cubagem rigorosa foi realizada empregando o método de Hohenadl com 10 secções: $5,15,25,35,45,55,65,75,85$ e $95 \%$ da altura total da árvore (Machado e Filho 2009). Posteriormente foram ajustados os modelos hipsométricos e volumétricos (Tabela 1), que apresentaram melhores desempenho de ajustes e estimativas, verificados por Leal et al. (2011), no mesmo povoamento. Do total de árvores da cubagem rigorosa (394), 70\% (276) fizeram parte dos ajustes dos modelos hipsométricos e volumétricos, e 30\% (118) foram utilizados para validação dos ajustes destes modelos. 
Tabela 1. Modelos hipsométricos que foram testados para obtenção da variável altura total (m) e modelos volumétricos que foram testados para obtenção do volume $\left(\mathrm{m}^{3}\right)$.

\begin{tabular}{c|l|l|c}
\hline Variável & \multicolumn{1}{|c|}{ Autor } & \multicolumn{1}{|c|}{ Modelo } & \multicolumn{1}{c}{ Equação } \\
\hline \multirow{2}{*}{ Altura } & Curtis & LnHT $=\beta 0+\beta 1 * \frac{1}{D A P}+\varepsilon$ & $(1)$ \\
\cline { 2 - 4 } & Trorey & $\mathrm{HT}=\beta 0+\beta 1 * \mathrm{DAP}+\beta 2 * \mathrm{DAP}+\varepsilon$ & $(2)$ \\
\hline \multirow{2}{*}{ Volume } & Schumacher e Hall $(\mathrm{Ln})$ & $\mathrm{LnVol}=\beta 0+\beta 1 * \mathrm{LnDAP}+\beta 2 * \mathrm{LnHT}+\varepsilon$ & $(3)$ \\
\cline { 2 - 4 } & Stoate & $\mathrm{Vol}=\beta 0+\beta 1 * \mathrm{DAP}+\beta 2 * \mathrm{DAP}{ }^{2} \mathrm{HT}+\beta 3 * \mathrm{HT}+\varepsilon$ & $(4)$ \\
\hline
\end{tabular}

Em que: $\mathrm{Ln}=$ logaritmo natural; $\mathrm{HT}=$ altura total; $\mathrm{DAP}=$ diâmetro a altura do peito $(1,3 \mathrm{~m}) ; \beta_{n}=$ coeficientes a serem ajustados.

Para selecionar as melhores equações volumétricas e hipsométricas foram analisadas as estatísticas de ajuste e precisão preconizadas por Draper e Smith (1980), sendo elas: análise gráfica dos resíduos, erro padrão da estimativa (Syx e Syx \%), correlação entre valores observados e as estimativas (r) e o coeficiente de determinação $\left(R^{2}\right)$. $\mathrm{O}$ teste de Wilcoxon-Mann-Whitney foi utilizado para verificar a diferença estatística ou não entre os valores observados na cubagem rigorosa e aqueles obtidos nas estimativas, ao nível de $5 \%$ de significância.

Para as estimativas de altura e volume por redes neurais artificiais (RNA) foi realizado o treinamento de uma RNA para cada uma das variáveis (altura e volume). Do total de árvores da cubagem rigorosa, $70 \%$ destas fizeram parte dos treinamentos e $30 \%$ foram utilizados para validação. O mesmo conjunto utilizado para as equações alométricas foi utilizado nas redes. O treinamento das redes neurais foi realizado por meio do programa NeuroForest versão 3.0 (Binoti et al. 2013c).

Para o treinamento e validação foram selecionadas redes do tipo Perceptron de múltiplas camadas, comumente conhecida por MLP (Multilayer Perceptron) (Heidari et at. 2016), e a função utilizada na ativação das RNA foi a sigmoidal (HAYKIN 2001). No presente estudo, o algoritmo de treinamento e validação foi o Resilient Propagation (RPROP), proposto por Riedmiller e Braun (1993), com taxas de aprendizagem variando entre 0 (zero) e 1 (um). Esta é uma das alternativas mais precisas, eficientes e recomendadas para RNA do tipo Multilayer Perceptron (Shiblee et al. 2010).

$\mathrm{Na}$ Figura 1 é possível verificar as arquiteturas das redes neurais para estimativa da altura $(\mathrm{m})$ e o volume $\left(\mathrm{m}^{3}\right)$. Para a altura $(\mathrm{HT})$, a arquitetura foi composta pelo: DAP $(\mathrm{cm})$ na camada de entrada; oito neurônios na camada oculta; a classe de DAP como variável categórica; e na camada de saída apenas a altura em metros (HT). Já para o volume $\left(\mathrm{m}^{3}\right)$, a arquitetura se diferenciou na camada de entrada, onde foi utilizado o DAP e HT, bem como na camada de saída onde utilizou-se o volume $\left(\mathrm{m}^{3}\right)$.

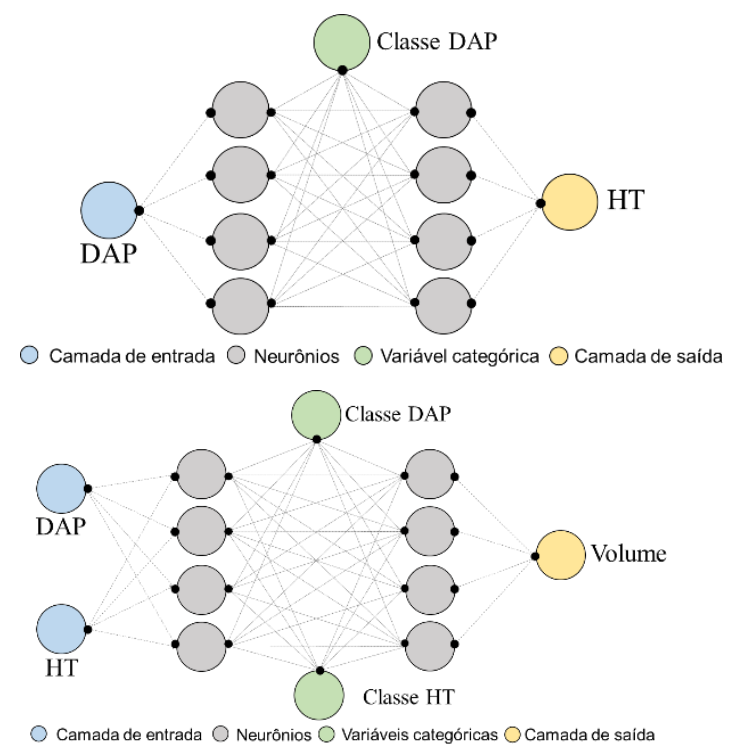

Figura 1. Arquiteturas das redes neurais artificiais, para estimativa da variável altura $(\mathrm{m})$ e volume $\left(\mathrm{m}^{3}\right)$, utilizando a base de dados da cubagem rigorosa.

A quantidade de neurônios utilizado na camada oculta foi igual a oito, número esse suficiente para resolver a maioria das abordagens no meio florestal, conforme preconizam Silva et al. (2009) e Miguel et al. (2016).

\section{Resultados e discussão}

Todos os métodos testados para estimativa da altura (m) em Eucalyptus urophylla S. T. Blake apresentaram estatísticas de ajustes e precisão satisfatórias, e como pode ser observado no $p$-valor (Tabela 2), tanto as equações ajustadas, quanto a rede neural, não apresentaram diferença significativa entre a altura observada e a estimada, ao nível de 5\% de significância. Tampouco entre o ajuste (A) e a validação (V) (Tabela 2).

Embora todos os métodos tenham apresentado estatísticas favoráveis, verificou-se que a rede neural apresentou maior desempenho nas estimativas, com erros relativos (Syx \%) em torno de $2,5 \%$, contra erros relativos acima de $10 \%$ para as equações alométricas de Curtis e Trorey. 


\section{Leal et al.}

Tabela 2. Estimativas da altura (m) por equações hipsométricas e por rede neural artificial (RNA), para a etapa de ajuste (A), treinamento (T) e validação (V), entre valores observados e as estimativas.

\begin{tabular}{|c|c|c|c|c|c|c|c|c|c|}
\hline \multirow{2}{*}{ Método } & \multirow{2}{*}{ Etapa } & \multicolumn{3}{|c|}{ Coeficientes ajustados } & \multirow{2}{*}{ Syx (m) } & \multirow{2}{*}{ Syx (\%) } & \multirow{2}{*}{$\mathrm{R}^{2}$} & \multirow{2}{*}{$\mathrm{r}$} & \multirow{2}{*}{ p-valor } \\
\hline & & $b 0$ & $b 1$ & $b 2$ & & & & & \\
\hline \multirow{2}{*}{ Curtis } & A & 3,56596 & $-7,38301$ & - & 2,20 & 11,2 & 0,83 & 0,91 & 0,979 \\
\hline & $\mathrm{V}$ & - & - & - & 2,30 & 11,7 & - & 0,90 & 0,319 \\
\hline \multirow{2}{*}{ Trorey } & $\mathrm{A}$ & 3,76791 & 1,37481 & $-0,01336$ & 2,00 & 10,4 & 0,84 & 0,92 & 0,914 \\
\hline & $\mathrm{V}$ & - & - & - & 2,10 & 10,8 & - & 0,92 & 0,745 \\
\hline \multirow{2}{*}{ RNA-H } & $\mathrm{T}$ & - & - & - & 0,26 & 1,3 & - & 0,99 & 0,985 \\
\hline & $\mathrm{V}$ & - & - & - & 0,47 & 2,5 & - & 0,99 & 0,950 \\
\hline
\end{tabular}

Em que: Syx = erro padrão da estimativa em metros; Syx \% = erro padrão da estimativa percentual; $\mathrm{R}^{2}=$ coeficiente de determinação ajustado; $\mathrm{r}=$ Correlação; RNA-H = altura (m); p-valor do teste Wilcoxon-Mann-Whitney.

Estudos desenvolvidos por Binoti et al. (2013 a), Castro et al. (2013), Özçelik et al. (2013), Binoti et al. (2014), Campos et al. (2016), Martins et al. (2016; 2017), empregando redes neurais artificiais para estimar a variável altura em plantios comerciais, também mostraram resultados superiores. Além disso, a utilização da inteligência artificial, como visto em alguns trabalhos, vem se tornando algo promissor para substituir os modelos tradicionais de regressão (Binoti et al. 2013b; Campos e Leite 2013).

Ainda que tenha sido notado eficiência nas estimativas, para todos os métodos estatísticos obtidos neste trabalho, a análise gráfica dos resíduos confirmou que há melhor desempenho nas estimativas, por rede neural, em detrimento das equações hipsométricas. Visto que, conforme pode ser observado na Figura 2, a dispersão dos resíduos das equações alométricas apresentou maior amplitude de desvios, com tendência em superestimar e subestimar alturas (m) superiores a 20 $\mathrm{m}$.

Enquanto isso, é possível notar que as estimativas por redes, a dispersão dos resíduos ficou exatamente sobre a linha zero da dispersão e distribuídos de forma homogênea, com alta correlação entre os dados observados e as estimativas, e desvios variando no máximo em $8 \%$.
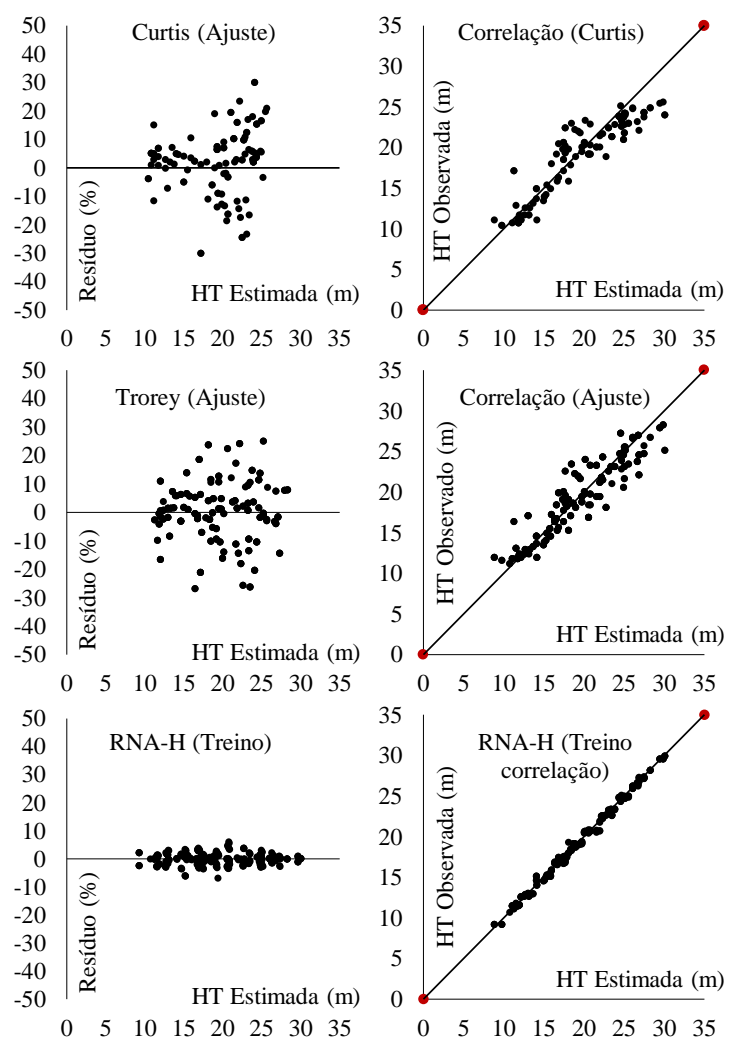
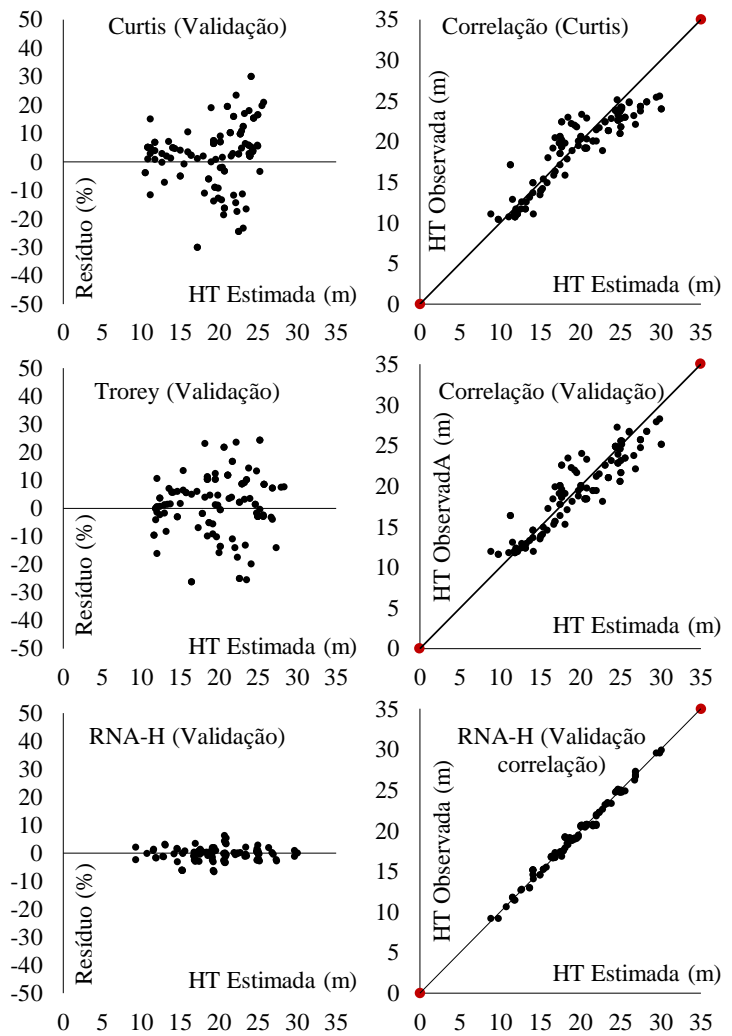

Figura 2. Distribuição gráfica dos resíduos (\%) para os modelos de Trorey, modelo de Curtis e por Rede Neural, bem como a correlação entre os valores estimados e observados. 
Mendonça et al. (2015), utilizaram a relação hiposométrica para estimativa da altura em eucalipto e constataram que a distribuição dos resíduos apresentou desvios superiores a 40\%. E trabalhos realizados por Binoti et al. (2013b) e Vendruscolo et al. (2015; 2017), utilizando redes neurais, apresentaram em suas pesquisas dispersão dos resíduos com desvios semelhantes ao encontrado neste estudo, onde também confirmam o excelente desempenho da RNA, em relação a análise de regressão.

Conforme pode ser observado na Tabela 3 a seguir, os resultados do p-valor atestam que as estimativas de volume, obtidas tanto pelas equações de Schumacher \& Hall e Stoate, quanto por rede neural, não diferiram da cubagem rigorosa, ao nível de $5 \%$ de significância. Essas equações apresentaram ainda alta correlação $(r=0,99)$ entre o volume observado e aquele advindo das estimativas, tanto no treinamento quanto na validação.

Apesar de todos os métodos testados para estimativa de volume de eucalipto apresentarem eficácia, a luz destes resultados, é possível notar que a rede neural apresentou maior desempenho entre os outros métodos. Isto foi evidenciado ao comparar os valores do erro padrão da estimativa (Syx \%) para o treinamento $(6,5 \%)$ e validação $(5,1 \%)$ da rede neural, em relação aos obtidos para Schumacher e Hall $(14,1$ e $11,7 \%)$ e Stoate $(11,6$ e $11,8 \%)$ respectivamente ajuste e validação.

Tabela 3. Estimativas do volume $\left(\mathrm{m}^{3}\right)$ por equações volumétricas e por rede neural artificial para a etapa de ajuste (A), treinamento (T) e validação.

\begin{tabular}{|c|c|c|c|c|c|c|c|c|c|c|}
\hline \multirow{2}{*}{ Método } & \multirow{2}{*}{ Etapa } & \multicolumn{3}{|c|}{ Coeficientes ajustados } & \multirow[b]{2}{*}{$B 3$} & \multirow{2}{*}{$\begin{array}{l}\text { Syx } \\
\left(\mathrm{m}^{3}\right)\end{array}$} & \multirow{2}{*}{$\begin{array}{l}\text { Syx } \\
(\%)\end{array}$} & \multirow{2}{*}{$\mathrm{R}^{2}$} & \multirow{2}{*}{$\mathrm{r}$} & \multirow{2}{*}{ p-valor } \\
\hline & & bo & $b 1$ & $b 2$ & & & & & & \\
\hline \multirow{2}{*}{ S \& H } & A & $-10,9793$ & 2,129445 & 1,09387 & - & 0,0200 & 14,1 & 0,97 & 0,99 & 0,785 \\
\hline & $\mathrm{V}$ & - & - & - & - & 0,0180 & 11,7 & - & 0,99 & 0,912 \\
\hline \multirow{2}{*}{ Stoate } & $\mathrm{A}$ & $-0,015475$ & $-0,000035$ & 0,000032 & 0,001326 & 0,0164 & 11,6 & 0,98 & 0,99 & 0,925 \\
\hline & $\mathrm{V}$ & - & - & - & - & 0,0182 & 11,8 & - & 0,98 & 0,981 \\
\hline \multirow{2}{*}{ RNA-V } & $\mathrm{T}$ & - & - & - & - & 0,0097 & 6,5 & - & 0,99 & 0,986 \\
\hline & V & - & - & - & - & 0,0068 & 5,1 & - & 0,99 & 0,924 \\
\hline
\end{tabular}

Em que: Syx = erro padrão da estimativa em metros; Syx \% = erro padrão da estimativa percentual; $\mathrm{R}^{2}=$ coeficiente de determinação ajustado; $r$ = Correlação; RNA-V = volume $\left(\mathrm{m}^{3}\right)$; p-valor do teste Wilcoxon-Mann-Whitney.
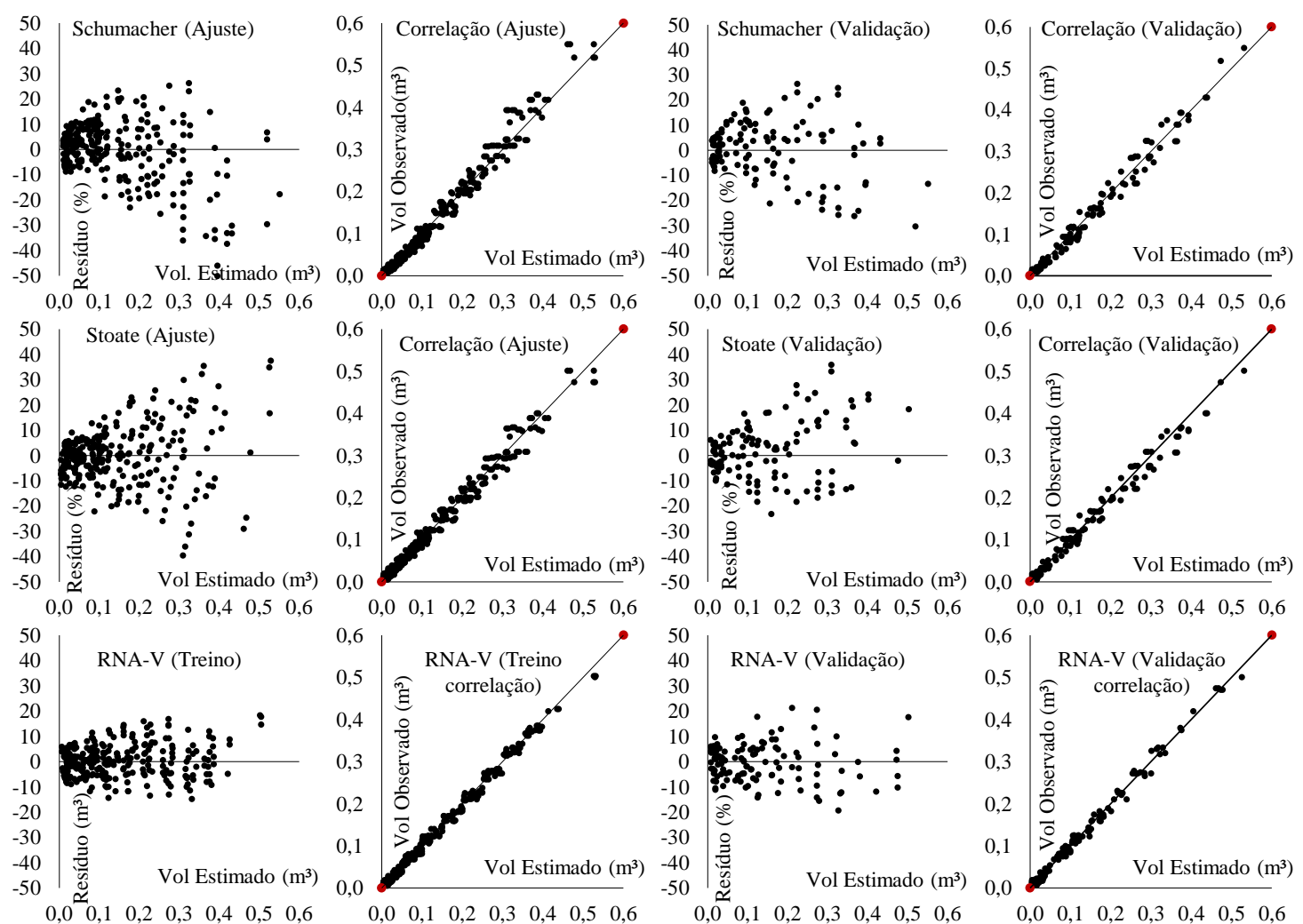

Figura 3. Distribuição gráfica dos resíduos $(\%)$ para os modelos de Schumacher e Hall e para Stoate e para rede neural artificial (RNA) e a correlação entre os valores estimados e observados.

Os ótimos desempenhos das RNA podem ser confirmados pela avaliação gráfica dos resíduos
(Figura 3), onde observa-se que a dispersão dos resíduos pela regressão variou entre $+30 \%$ e $-40 \%$ 
para a equação de Schumacher e Hall, e entre $+40 \%$ e $-40 \%$ para a equação de Stoate. Enquanto isso, a dispersão dos resíduos por redes neurais variou em $20 \%$ aproximadamente, e com distribuição mais homogenia dos resíduos, próximos a linha de tendência.

Corroboram com estes resultados o estudo realizado por Leal et al. (2015), onde os autores confirmam que o desempenho da RNA foi superior quando comparado às equações de regressão tradiconais. Ademais, Gorgens et al. (2009; 2014), Binoti et al. (2014; 2015) e Miguel et al. (2016), também comprovam a eficácia da RNA para estimativa volumétrica. Segundo Silva et al. (2009), a tecnologia das RNA proporciona boa adaptação e é bastante recomendada para a previsão volumétrica da produção de florestas plantadas.

\section{Conclusão}

Tanto as equações ajustadas quanto as redes neurais treinadas e validadas foram eficientes para estimativa de altura e volume em E. urophylla. No entanto, observando os dados obtidos nesta pesquisa, as RNA apresentaram maior desempenho em relação às estimativas obtidas, tanto para a altura $(\mathrm{m})$ quanto ao volume $\left(\mathrm{m}^{3}\right)$.

\section{Referências}

Almeida AQ, Mello AA, Dória Neto AL, Ferraz RC (2014). Relações empíricas entre características dendrométricas da Caatinga brasileira e dados TM Landsat 5. Pesquisa Agropecuária Brasileira, 49 (4):306-315. doi:10.1590/S0100 204X2014000400009

Ashraf MI, Meng FR, Bourque CPA, Maclean DA (2015) A novel modelling approach for predicting forest growth and yield under climate change. PloS one, 10(7): 1-18.

doi.org/10.1371/journal.pone.0132066

Azevedo TL, Mello A A, Ferreira RA, Sanquetta CR, Nakajima NY (2011) Equações hipsométricas e volumétricas para um povoamento de Eucalyptus sp. localizado na FLONA do Ibura, Sergipe. Revista Brasileira de Ciências Agrárias, 6(1):105 - 112. doi:10.5039/agraria.v6i1a861

Binoti MLMS, Leite HG, Binoti DHB, Gleriani JM (2015) Prognose em nível de povoamento de clones de eucalipto empregando redes neurais artificiais. Revista Cerne, 21(1):97-105. doi: 10.1590/01047760201521011153

Binoti DHB, Binoti MLMS, Leite HG (2014)

Configuração de redes neurais artificiais para estimação do volume de árvores. Ciência $d a$ Madeira, 5(1):58-67.

doi:10.5039/agraria.v11i1a5354
Binoti DHB, Binoti MLMS, Leite HG, Silva A (2013a) Redução dos custos em inventário de povoamentos equiâneos. Revista Brasileira de Ciência Agrárias, 8(1):125-129. doi: 10.5039/agraria.v8i1a2209

Binoti DHB, Binoti MLMS, Leite HG (2013b) Redução dos custos em inventário de povoamentos equiâneos utilizando redes neurais artificiais. Agrária, 8(1):125-129. doi: 10.5039/agraria.v8i1a2209

Binoti DHB, Binoti MLMS, Leite HG (2013c) NeuroForest Star. Patente: Programa de Computador. Número do registro: 13410-5, data de registro: 30/04/2013, título: "NeuroForest Star", Instituição de registro: INPI - Instituto Nacional da Propriedade Industrial.

Braga AP, Carvalho, APLF, Ludermir TB (2007) Redes neurais artificiais: teoria e aplicações. $2^{\text {th }}$ Edição. Rio de Janeiro: LTC, 248p.

Campos BPF, Silva GF, Binoti DHB, Mendonça AR, Leite HG (2016) Predição da altura total de árvores em plantios de diferentes espécies por meio de redes neurais artificiais. Pesquisa Florestal Brasileira,36(88):375-385, doi: 10.4336/2016.pfb.36.88.1166

Campos JCC, Leite HG (2013) Mensuração florestal: perguntas e respostas. $4^{\text {th }}$ Edição.Viçosa: UFV, 605p.

Castro RVO, Soares CPB, Leite HC, Souza AL, Nogueira GS, Martins FB (2013). Individual Growth Model for Eucalyptus Stands in Brazil Using Artificial Neural Network. ISRN Forestry, 2, p.1-12, 2013. doi.org/10.1155/2013/196832

David HC, Miranda ROV, Wlker J, Fiorentin LD, Ebling AA, Silva PHBM (2016) Strategies for stem measurement sampling: a statistical approach of modelling individual tree volume. Cerne, 22(3):249 - 260. doi.org/10.1590/01047760201622032155

Debastiani AB, Martins LP, Santos KSM, Corte APD, Netto SP, Sanqueta CR (2019) Distribuição do diâmetro de copa e diâmetro quadrático de Araucaria angustifolia e Pinus taeda. Ciência Florestal, 29(1): p. 270-280, 2019. doi.org/10.5902/1980509829219

Draper NR, Smith H (1980) Applied Regression Analysis. $2^{\text {th }}$ Edição. New York, John Wiley e Sons, Inc. 709p. 
Fernandes MM, Sousa L, Silva JPM, Araújo EF, Fernandes MRM, Nobrega RSAN (2019). Redes Neurais Artificiais na estimação de variáveis biométricas de mudas de espécies florestais produzidas em diferentes substratos. Revista Ciências Agroveterinárias, 18(1):47-58. doi: $10.5965 / 223811711812019047$

Gonçalves JC, Oliveira AD, Carvalho SPC (2017) análise econômica da rotação florestal de povoamentos de eucalipto utilizando a simulação de Monte Carlo. Ciência Florestal, 27(4)p: 1339-1347. doi.org/10.5902/1980509830215

Gorgens EB, Leite HG, Gleriani JM, Soares CPB, Ceolin A (2014) influência da arquitetura na estimativa de volume de árvores individuais por meio de redes neurais artificiais. Revista Árvore, 38(2):289-295. doi.org/10.1590/S010067622014000200009 .

Gorgens EB, Leite HG, Santos HS, Gleriani JM (2009) Estimação do volume de árvores utilizando redes neurais artificiais. Revista Árvore, 33(6):11411147. doi:.org/10.1590/S0100-67622009000600016

Haykin, S (2001) Redes neurais: princípios e prática. $2^{\text {th }}$ Edição. Porto Alegre, 900p.

Heidari E, Dobati, MA, Movahedirad S (2016) Accurate prediction of nanofluid viscosity using a multilayer perceptron artificial neural network (MLPANN). Chemometrics and Intelligent Laboratory Systems, 155:p.73-85. doi.org/10.1016/j.chemolab.2016.03.031

IBÁ - Indústria Brasileira de Árvores (2019). Relatório 2018. Disponível em: < https://iba.org/datafiles/publicacoes/relatorios/ibarel atorioanual2019.pdf >. Acesso em: junho/2020.

Leite HG, Silva MLM, Binoti DHB, Fardin L, Takizawa FH (2011) Estimation of inside-bark diameter and heartwood diameter for Tectona grandis Linn. trees using artificial neural networks. European Journal of Forest Research, 130(2):263269. doi.org/10.1007/s10342-010-0427-7

Leal FA, Miguel EP, Matricardi EAT (2020) Estimates of Deforestation Rates in Rural Properties in the Legal Amazon. Floresta e Ambiente, 27(2):2 -8, doi.org/10.1590/2179-8087.028317

Leal FA, Miguel EP, Matricardi EAT, Pereira RS (2015) Redes neurais na estimativa de volume em um plantio de eucalipto em função de fotografias hemisféricas e números de árvores. Revista Brasileira de Biometria, 33(2):233-249.
Leal FA, Miguel EP, Matricardi EAT (2011) Mapeamento de unidades produtivas utilizando a interpolação geoespacial krigagem a partir do inventário florestal em um povoamento de Eucalyptus urophylla S. T. Blake. Enciclopédia Biosfera,7(13):727-745.

Lima CPJ, Leão ARJ (2013) Dinâmica de Crescimento e Distribuição Diamétrica de Fragmentos de Florestas Nativa e Plantada na Amazônia Sul Ocidental. Floresta e Ambiente, 20(1):70-79. doi.org/10.4322/floram.2012.065.

Machado AS, Filho AF (2009) Dendrometria. $2^{\text {th }}$ Edição. Guarapuava: UNICENTRO, 309p.

Miguel EP, Téo JS, Nascimento RGM, Leal FA, Pereira RS, Rezende AV (2016) Artificial intelligence tools in predicting the volume of trees within a forest stand. African Journal of Agricultural Research, doi.org/10.5897/AJAR2016.11015

11(21):1914-1923.

Miguel EP, Rezende AV, Leal FA, Matricardi EAT, Vale AT, Pereira RS (2015) Redes neurais artificiais para a modelagem do volume de madeira e biomassa do cerradão com dados de satélite. Pesquisa Agropecuária Brasileira, 50(9):829-839. doi.org/10.1590/S0100-204X2015000900012.

Miguel EP, Leal FA, Ono HÁ, Leal UAS (2014) Modelagem na predição do volume individual em plantio de Eucalyptus urograndis. Revista Brasileira de Biometria, 32(4):584-598.

Martins APM, Debastiani AB, Pelissari AL, Machado AS, Sanqueta CR (2017) Estimativa do Afilamento do Fuste de Araucária Utilizando Técnicas de Inteligência Artificial. Floresta $e$ Ambiente, 24:1-10. doi.org/10.1590/21798087.023416

Martins ER, Binoti MLMS, Leite HG, Binoti DHB, Dutra GC (2016) Configuração de redes neurais artificiais para estimação da altura total de árvores de eucalipto, Revista Brasileira de Ciências Agrárias, 11(2):117-123. doi:10.5039/agraria.v11i1a5354

Mendonça AR, Caravalho SPC, Calegario N (2015) Modelos hipsométricos generalizados mistos na predição da altura de Eucalyptus sp. Revista Cerne, 21(1):107-115.

doi.org/10.1590/01047760201521011191

Mirzaei, M, Aziz J, Mahadavi A, Rad AM (2016) Modeling frequency distributions of tree height, diameter and crown area by six probability functions for open forests of Quercus persica in Iran. Journal of Forestry Research, 27(4):901-906. doi.org/10.1007/s11676-015-0194-X 
Mugasha WA, Mwakalukwa EE, Luoga E, Malimbwi RE, Sahabu E, Silayo DS, Sola G, Grete P, Henrt M, Kashindye A (2016) Allometric Models for Estimating Tree Volume and Aboveground Biomass in Lowland Forests of Tanzania. International Journal of Forestry Research, 2016(4):1-13. DOI: 10.1155/2016/8076271

Nunes MH, Görgens EB (2016) Artificial Intelligence Procedures for Tree Taper Estimation within a Complex Vegetation Mosaic in Brazil. PloS one, 11:1-16. doi.org/10.1371/journal.pone.0154738

Özçelik R, Diamantopoulou MJ, Brooks JR, Júnior HVW (2010) Estimating tree bole volume using artificial neural network models for four species in Turkey. Journal of Environmental Management, 91(3):742753. doi.org/10.1016/j.jenvman.2009.10.002

Özçelik R, Dimantopoulou, Mj, Brooks J.R, Wiiant Junior HV (2013) Estimating Crimean juniper tree height Using Nonlinear regression and artificial neural network models. Forest Ecology and Management, 306:52-60. doi.org/10.1016/j.jenvman.2009.10.002

Riedmiller M, Braun HA (1993) direct adaptive method for faster backpropagation learning: the RPORP algorithm. In: IEEE International Conference on Neural Networks, 1993, San Francisco. Proceedings. New York: IEEE, 1:586591. doi: 10.1109/ICNN.1993.298623.

Santos AT, Mattos PP, Braz EM, Rosot NC (2015) Determinação da época de desbaste pela análise dendrocronológica e morfométrica de Ocotea porosa (Nees \& Mart.) Barroso em povoamento não manejado. Ciência Florestal, 25(3): 699-70. doi.org/10.5902/1980509819620

Silva MLM, Binoti DHB, Gleriani JM, Leite HG (2009) Ajuste do modelo de Schumacher e Hall e aplicação de redes neurais artificiais para estimar volume de árvores de eucalipto. Revista Árvore, 33(6):1133-1139, 2009. doi.org/10.1590/S010067622009000600015

Shiblee M, Chandra B, Kalra PK (2010) Learning of geometric mean neuron model using resilient propagation algorithm. Expert Systems with Applications, 37(12):7449-7455. doi.org/10.1016/j.eswa.2010.04.018

Vibrans AC, Moser P, Oliveira LZ, Maçaneiro JP (2015) Generic and specific stem volume models for three subtropical forest types in southern Brazil. Annals of Forest Science, 72:865-874. doi: 10.1007/s13595-015-0481-X
Vendruscolo DGS, Drescher R, Souza HS, Moura, JPVM, Mamoré FMD, Siqueira TAS (2015) Estimativa da altura de eucalipto por meio de regressão não linear e redes neurais artificiais. Revista Brasileira de Biometria, 33(4):556-569.

Vendruscolo DGS, Chaves AGS, Medeiros RA, Silva RS, Souza HS, Drescher R, Leite HC (2017) Estimativa da altura de árvores de TectonagrandisL.f. utilizando regressão e redes neurais artificiais. Nativa, 5(1):52-58. DOI: 10.5935/2318-7670.v05n01a09 